\title{
Cultura popular y modernidad temprana ${ }^{1}$
}

\section{Eduardo Kingman Garcés}

Facultad Latinoamericana de Ciências Sociales - Flacso-Ecuador

\section{Ciudad y vida cotidiana}

Desde los inicios de la República, y como parte de la herencia colonial, el mundo ciudadano se sintió identificado con lo urbano y con lo letrado; sin embargo en la vida cotidiana los límites que separaban lo popular de lo no popular, lo urbano de lo no urbano, lo escriturado de lo no escriturado, eran, muchas veces, difusos. Si bien la sociedad quiteńa estaba fuertemente condicionada por el imaginario de la separación entre la república de indios y de españoles y de un sistema estamental y jerárquico, la lógica a partir de la cual se organziaba la vida cotidiana, era muchas veces la de la yuxtaposición de lo distitnto órdenes sociales. En un país en el que los órganos del estado estaban poco desarrollados, la administración de las poblaciones pasaba por relaciones personalizadas, que al mismo tiempo que reproducian las difrencias, favorecían la mezcla e hibridación. Esto ha sido asumido como barroco, pero hay que entender el barroco no sólo como un ethos sino algo anclado en una economía y una sociología política. El barroco se mostraba, sobre todo, en determinados espacios, en los que se reproducía lo que Baktin llama el "espíritu de la plaza pública".

Antes que de una "modernidad barroca", resultado de un "encuentro civlizatorio" deberíamos hablar de un barroco popular paralelo o yuxtapuesto a las formas de cultura seria del estado y de la iglesia. Lo que se llamaba barroco americano en el siglo XVII, e incluso en los siglos XVIII y XIX, y una de cuyas mayores expresiones fue la religiosidad, sobrevivió y se reprodujo, como cultura popular, fuera de las esferas oficiales, hasta avanzado el siglo XX ( $\mathrm{y}$ en parte hasta ahora). Podríamos decir que la virtud mayor de ese barroco fue la de permitir la circulación de elementos culturales entre los estratos bajos y altos, algo distinto al proyecto republicano o ciudadano de los siglos XIX y XX, cuya característica básica fue la exclusión, a la vez que la imposición de criterios y valores. 
Pese a los esfuerzos civilizatorios del estado y la iglesia, desarrollados desde la segunda mitad del siglo XIX y orientados a generar separaciones sociales y culturales, la cultura popular siguió teniendo un peso significativo en la vida cotidiana hasta avanzado el siglo XX. Cuando hablamos de cultura popular nos referimos a un espacio de producción, circulación y consumo que atraviesa a distintas clases, etnias y grupos sociales, aunque no necesairmante sea vivida del mismo modo por todos. A pesar de las fronteras étnicas, bajo determinadas circunstancias, no sólo se dio lugar a la reproducción del espíritu de la plaza pública, sino que la gente reinventaba constantemente sus imaginarios y formas de representación, a partir de elementos tomados de dos y más mundos. Existían aún elementos de una cultura en común y, al mismo tiempo, distintas vivencias con relación a ella, de acuerdo a la posición que se ocupaba en el orden jerárquico. Por otro lado, se daba un proceso avanzado de extirpación cultural, que afectaba tanto a los sectores populares e indígenas como a sectores medios y de la èlite. En la ciudad este proceso tomaba la forma del ornato ${ }^{2}$.

La necesidad de marcar los espacios sociales y físicos a partir de criterios de ornato, distinción y decencia se hacía presente en todos los aspectos de la cultura ciudadana. Con la modernidad temprana se profundizaron los conflictos entre esa cultura y el mundo indígena y popular. $\mathrm{Al}$ mismo tiempo, como veremos en este artículo, la cultura popular tomó fuerza y significado.

\section{Los ámbitos de la vida popular}

Para entender el funcionamiento de la cultura popular tendríamos que comenzar defiiendo cuales eran sus bases de fucionamiento. Hacía finales del siglo XIX y hasta avanzado el siglo XX Quito podía ser caracterizada como una ciudad de Antiguo Régimen, tanto por el peso que tenía en ella el sistema de hacienda como por su estrecha relación con el campo. Para muchos se trataba de una ciudad colonial, incluso conventual, en la que predominaban los oficios, pero este tipo de caracterizaciones puede hacernos perder de vista los cambios que se estaban produciendo, a veces de manera imperceptible, en las relaciones sociales y en los tratos cotidianos, en las formas de gobernabilidad, los sistemas de representación y los imaginarios. Si se sigue la pista a esos cambios se podría decir que no sólo se estaba abriendo las puertas a una modernización y una modernidad incipientes sino que en medio de ese proceso lo que se estaba poniendo en cuestión era el propio orden aristocrático. Me refiero tanto a las reformas que se produjeron en el agro durante la primera mitad del siglo XX y que de un modo u otro influyeron en la ciudad, como a la dinámica que fueron imprimiendo los nuevos sectores sociales en la vida de la urbe. 
Aún cuando se podría decir que hasta la primera mitad del siglo XX Quito era todavía una ciudad tradicional no se trataba de una sociedad estática ${ }^{3}$. Una descripción de Quito hacia 1938, hecha por unos inmigrantes judíos que llegaron al Ecuador da pistas para entender el funcionamiento de una ciudad que sin ser industrial o moderna en el sentido de las europeas, mantenía una dinámica relacionada, en el caso de la descripción, con la vida popular. El texto es del ańo 1975 :

El que hoy en día llega a Quito por primera vez, difícilmente podrá imaginarse el encanto del pequeño centro colonial, tan alejado del mundo con su casi histórica vida sin apuros y empujones. Las montańas que rodean la ciudad, a la vez muro protector y corona natural, formaban el horizonte, al fondo de los callejones y pasajes ascendentes. Al mediodía los almacenes y oficinas cerraban por dos horas. Aparte de unas pocas fábricas textiles, aún sin importancia, prácticamente no existía ninguna industria, pero sí un sinnúmero de artesanos, carpinteros, zapateros, sastres y costureras, cerrajeros y mecánicos muy hábiles y capaces de reparar las cosas más viejas y desgastadas. ${ }^{4}$

En una ciudad de este tipo no se puede hablar de un espacio social uniforme. Si bien existía una tendencia a jerarquizar los espacios, llevada por los criteiros del ornato, el centro era un lugar de disputas. Las fotografías de las primeras décadas del siglo XX, al mismo tiempo que muestran espacios diferenciados, marcados por el ornato, evidencian una fuerte presencia indígena y chola en muchas calles y en plazas centrales como Santo Domingo y San Francisco. Estamos hablando de un momento relativamente largo de permanencias y mutaciones culturales (con sus idas y venidas, retrocesos y avances, repeticiones y cambios).

Las chicherías, por ejemplo, estaban presentes, como ámbitos de socialización indígena, dirigidos por mujeres, en zonas cercanas a lo que para ese entonces se consideraba la parte central. Aunque desde la segunda mitad del siglo XIX se habían dado disposiciones orientadas a su reubicación hacía la periferia ${ }^{5}$ eso no se cumplía necesariamente. Otros espacios de socialización en los que se desarrollaba un rico mundo popular eran las lavanderías y lavaderos de ropa, las hospederias, los puestos de venta de objetos "para indios y cholos", los centros de diversiones populares como las rifas, las peleas de gallos, los juegos de pelota. Además de las chicherías, las fondas y figones, espacios administrados principalmente por mujeres, había sitios que hacían de fronteras entre lo urbano y lo rural como los mercados y las estaciones de ferrocarril y de autobuses interparroquiales e interprovinciales.

En términos de su configuración social se podría decir que Quito se estaba modernizando, dando lugar a la formación de nuevos sectores sociales, aùn 
cuando conservaba muchos elementos de una ciudad seńorial. Esta imbicaciòn de antiguas relaciones patrimoniales con formas modernas ha sido concebida como postcolonialismo. A más de una servidumbre urbana, traída en gran parte de las haciendas, había en Quito un peonaje urbano, formado en parte por los indígenas de las comundiades cercanas que hacían por turnos el servicio de la ciudad (Sistema de trabajo subsidiario) y de otro lado por trabajadores independientes y semi independientes ocupados en la construcción, el acarreo de mercancías, el cuidado de jardines y huerta urbanas a cambio de un salario.

En la ciudad existían muchas ocupaciones ambiguas que estaban relacionadas con la servidumbre pero conservaban un cierto nivel de autonomìa, como las lavanderas, aplanchadoras, costureras, relacionadas con "las casas" o las de trabajadoras y trabajadores relacionados con instituciones públicas y semipúblicas como las sirvientas de hospital o los sirvientes municipales Se trataba de ocupaciones que dependían de la relacióncon redes personalizadas de trabajo, servicios y favores propias de una situación neocolonial. Los niveles de autonomía de estos sectores (cuando se daban) no provenían tanto de las ocupaciones como de la posiblidad de vivir o de trabajar en espacios separados. Las lavanderas de El Censo o las de la quebrada del Batán trabajaban para las casas de familia pero tenían la posibilidad de mantener cierta independencia con respecto a ellas, debido a que su labor se realizaba en espacios distintos del doméstico. E igual sucedía con las costureras que comenzaron a elaborar ropa barata para las capas populares. De acuerdo con el Censo de 1906, el número de costureras (2.310) era bastante alto y denota la incorporación de la mujer del pueblo a los espacios abiertos por la primera modernidad.

Los grados de autonomía son, en todo caso, difíciles de juzgar ya que se trataba de una sociedad corporativa basada en redes, lealtades y clientelas y en sistemas de trabajo y aprendizaje basados en relaciones personales. Un aprendiz de sastre se sujetaba a la autoridad del maestro que lo acogía en su taller y algo parecido sucedía con el resto de oficios. Los artesanos estaban agremiados y aunque ya se había dado una diferenciación de los oficios, como acertadamente seńala Luna ${ }^{6}$, no se habían roto todos los lazos de dependencia recíproca que unían a maestros, oficiales y aprendices. Me refiero a una dependencia práctica, propia de la organización manual del trabajo, pero también a elementos de una cultura en común, sentidos, gustos comunes.

Aunque desde las primeras décadas del siglo XX los trabajadores buscaron formas de organización autónomas, como los sindicatos, diferenciados de la organización gremial, se daban una serie de lazos corporativos que iban más allá de las diferenciaciones sociales y de intereses en el interior de los gremios. 
La vida de los gremios en el siglo XIX e inicios del XX estuvo estrechamente relacionada con la organización de la Policía. Por decreto ejecutivo del $1^{\circ}$ de septiembre de 1884 la intendencia de Policía debía llevar un registro de todos los individuos varones de 18 a 60 ańos de edad, nacionales y extranjeros que aprendían o ejercían un arte o profesión. La acepción de gremio y agremiación era bastante amplia ya que estaba relacionada con el desarrollo del sentido corporativo en todas las esferas de la vida social. Se entiende que la "sociedad" y el estado se relacionaban con esas corporaciones, debidamente organizadas; éstas servían, a su vez, de mediadoras en las relaciones entre los individuos. En el caso específico de los gremios artesanales, la Policía, al mismo tiempo que garantizaba su funcionamiento, intentaba mantener un control corporativo sobre sus miembros. En realidad no se trataban de disposiciones recientes; muchas de ellas tenían sus antecedentes en las el Renacimiento europeo. Lo reciente era, posiblemente, su organización en relación con el estado. En principio, los miembros de los diferentes gremios artesanales tenían la obligación de reunirse anualmente en la intendencia de cada cantón para nombrar a sus maestros mayores. Entre los gremios convocados por la Intendencia de Guayaquil en el ańo de 1884 estaban los de los panaderos, zapateros, talabarteros, sastres, encuadernadores, albañiles, aserradores, calafates, tintoreros, caldereros, fundidores, herreros, maquinistas, cigarreros, hojalateros, colchoneros, fotógrafos, grabadores, marmolistas, pintores, gasfiteros, toneleros, bauleros, peluqueros, plateros, sombrereros, relojeros y tipógrafos. Como se puede ver se trataba de una serie de oficios algunos de los cuales estaban directamente relacionados con la modernización de la sociedad.

Las disposiciones policiales estaban dirigidas a garantizar el cumplimiento de las obligaciones de los artesanos, debido al carácter relativamente autónomo de su actividad que les hacía disponer de su tiempo de modo autárquico. Una de las contravenciones más frecuentes, juzgada por los comisarios de policía, era la de incumplimiento de obra, sobre todo en épocas de festividades. No es que no existieran mecanismos de contratación sino que no se los cumplía. Es por eso que, dentro de los propios gremios, se establecían criterios morales, dirigidos a defender su prestigio, a la vez que su disciplina interna, basados en la honradez y el espíritu del trabajo del artesano; esto permitía diferenciar a los buenos artesanos de los malos. La Policía, al igual que la Iglesia, avalaba la acción moralizadora de los gremios.

Sin embargo, tal como ha mostrado Luna, a inicios del siglo XX se comienza a vivir el descalabro de las formas de organización gremiales, las mismas que van siendo sustituidas tanto por las sindicales como por las organizaciones informales. En realidad desde finales del siglo XIX buena parte de las actividad artesanal escapaba al control de los gremios, no sólo por los procesos de diferenciación internos sino porque la mayoría de los nuevos artesanos no estaban agremiados 
(muchos venían de otras poblaciones y se instalaban al margen de los gremios) o formaban parte de esa infinidad de personas sin oficio fijo que se veían en la necesidad de "saber de todo" y "hacer de todo", fluctuando de una a otra ocupación y a los que muchas veces resultaba ventajoso contratar. En la misma tarea de aprendizaje no todos los jóvenes permanecían en un mismo tipo de trabajo sino que pasaban por distintos oficios antes de decidirse por uno. Don Manuel Tumipamba comenzó aprendiendo zapatería antes de decidirse por la albañilería, mientras que Manuel Recalde fue aprendiz de panadero y luego carpintero para terminar como comerciante. ${ }^{7}$ Se trataba de un largo proceso de disolución de los talleres artesanales tradicionales como resultado del desarrollo de las manufacturas y de las fábricas, así como por la ampliación de los productos importados, de menor precio y mayor variedad, en el mercado.

La Policía a la vez que promovía la organización gremial, garantizaba su funcionamiento interno. Se sabe que los maestros de los gremios debían registrar a sus agremiados en la Policía. Ésta, además, intermediaba en sus conflictos internos, avalizaba el nombramiento de sus directivos. Así, por ejemplo, Se normaba el trabajo de los aprendices de modo que ningún oficial o aprendiz menor de edad pudiera pasar de un taller a otro sin permiso de sus padres o guardadores. Muchos menores eran reclutados para trabajar en casas, bodegas, almacenes como sirvientes o en talleres, curtiembres, panaderías como aprendices. De acuerdo con denuncias presentadas en las comisarías de Pichincha, la mayoría de menores venían del campo y de otras ciudades y eran traídos con engaños y ofrecimientos. En otros casos eran entregados directamente por sus padres a los maestros de taller. Los menores se alojaban en los talleres pero no recibían nada a cambio, fuera de la alimentación. La utilización de un número grande de aprendices sería una de las bases de la organización del trabajo y de la ganancia en los talleres artesanales y manufactureros. La Escuela de Artes y Oficios contribuyó a la formación de un personal especializado, de manera independiente de los talleres. Se trataba de formar trabajadores calificados y mandos medios, entrenados no sólo en el trabajo manual sino en el uso de máquinas. La escuela de artes y oficios incluyo a mujeres entre sus estudiantes, aunque en una proporción menor que los hombres. A ellas se les daba una formación diferenciada, que les preparaba para trabajar como costureras independientes o como trabajadoras de las manufacturas.

En cuanto a la industria, estamos hablando de algo incipiente. De acuerdo con datos del Ministerio de Trabajo, consignados por el salubrista Dimas Burbano $^{8}$ en 1934 - cuando Quito ya había entrado aparentemente en la modernidad- apenas el $7 \times 1.000$ de la población (1.222 personas) trabajaba como obrero industrial. Esto quiere decir que la clase trabajadora estaba formada por artesanos, informales y sirvientes antes que por obreros. 
Hacia 1937 los trabajadores industriales se habían duplicado, pero aún así su peso en el conjunto de la población ocupada seguía siendo poco significativo. Dimas Burbano utiliza, en este caso, un parámetro mucho más estricto que el acostumbrado para hablar de industria, ya que se refería únicamente a las fábricas, dejando de lado los talleres y las manufacturas.

Un mundo más fluctuante era el de los trajines callejeros; aparte de las vendedoras y vendedores con puestos fijos en los mercados y tiendas, había un grupo numeroso de regatonas que se movía por toda la ciudad con sus productos. Se trataba de un comercio ambulante de productos agrícolas, leña, ropa, alimentos preparados. Buena parte de ese comercio provenía de los pueblos y comunidades de indios cercanos a la urbe, pero también de indígenas y mestizos urbanos entre los cuales ocupaban, como ya se dijo, un lugar destacado las mujeres. ${ }^{9}$ A más de esto estaban los hornos de pan, los lugares donde se preparaban y vendían las chichas, las picanterías, las traperías y cachinerías. El Aguarico era conocido por sus chicherías mientras que la calle Chile era el lugar de las traperías y cachinerias.

Todo hace pensar que el comercio popular imprimía una dinámica paralela a la ciudad y que esa dinámica no necesariamente se oponía a la del comercio formal. La parte del comercio fijo que funcionaba en pulperías, abarrotes, barracas, cajones estaba, a su vez, estrechamente relacionado con el ambulatorio. Pero no sólo se trataba del comercio popular, ya que también las casas de comercio estaban relacionadas con el comercio al detalle. Justamente en los albores del primer centenario de la Independencia (1922) hubo un debate sobre si se debía permitir o no que las buhoneras sigan manteniendo sus pequeńos negocios en la Plaza Grande. En el debate se mostraba que ellas respondían a la dinámica de los almacenes y comercios formales, lo cual era parcialmente cierto. A esta dinámica callejera habría que sumar la de los arrieros, cargueros y carreteros, que facilitaban el intercambio de productos entre distintas ciudades, la ciudad y el campo y en la misma ciudad. Ni siquiera con el ferrocarril, el tranvía y, más tarde, con la introducción de transporte motorizado, éstos desaparecieron del todo.

Sería equivocado pensar que no se reproducían las fronteras entre la población indígena y la blanco mestiza, aspecto en el que acertadamente pone énfasis Andrés Guerrero ${ }^{10}$. Pero, a diferencia del campo la ciudad se caracterizaba por un flujo constante de gente, productos, personas e información, lo que imprimía un ritmo distinto a las relaciones cotidianas. El comercio, en particular, introducía una dinámica de tratos y relaciones diferente al que se daba en las zonas rurales. La ciudad estaba llena de pequeńos negocios instalados en los bajos de las casas. Hacía el ańo 1912 se registraron 1.394 casas y 2.400 tiendas en 358 cuadras de Sur a Norte, y 1.140 casas y 1.729 tiendas en 310 
cuadras de oriente a occidente ${ }^{11}$. Es cierto que de las 4.830 tiendas que tenía la ciudad un buen porcentaje de ellas servía de cuartos de inquilinato, pero otro tanto estaba destinado al comercio o a talleres o, simplemente, a uno y otro uso. Se decía que "tras de la tienda siempre había una trastienda y tras de cada patio un traspatio." ${ }^{12}$ Esto estaba relacionado con la yuxtaposición de usos y actividades en un mismo espacio.

Un rubro importante del comercio era la carne. El faenamiento de animales en mataderos públicos buscaba garantizar su calidad, pero también el cobro de tasas por parte del Municipio. Las carnicerías funcionaban tanto en la zona urbana como en las parroquias. Uno de los pedidos que hacía el Intendente de Policía al Ministro del Interior, en el ańo de 1917, era la presencia de celadores en el matadero, con el fin de evitar los escándalos y los abusos de los introductores de ganado. De acuerdo al mismo documento, sin la presencia de ellos sería imposible conservar la disciplina en los mataderos.

El impuesto "de Rastro" se cobraba hacia el ańo 1884 tanto en Quito como en las parroquias de Santa Prisca, Guapulo, Magdalena y Chimbacalle ${ }^{13}$. Estas parroquias tenían una fuerte composición indígena. De acuerdo con disposiciones que no siempre se cumplían, nadie podía despostar ganado sin conocimiento del teniente político, ni se podía vender la carne fuera de la población, a no ser que se la trasladase en carretas de modo que "no se oree demasiado". Lo más frecuente era llevar el ganado en pie hasta los mataderos de la ciudad. Los llamados introductores de carne eran, generalmente, mestizos que recorrían los campos comprando y revendiendo en Quito, pero es muy probable que en ese negocio hayan participado algunos indígenas. ${ }^{14} \mathrm{La}$ forma en que se transportaba la carne preocupaba a los médicos higienistas. Según sus descripciones se lo hacía en carretas sucias y deterioradas "ofreciendo un espectáculo nada estético"15. Algo parecido a la carne sucedía con la leche e incluso el pan: no tenía sentido traerlos desde muy lejos ya que pasaba mucho tiempo antes de de que pudieran ser consumidos. Sólo con el ferrocarril comenzaron a llegar productos perecibles de zonas más lejanas, así, por ejemplo, el pan especial de Ambato y el afamado pan de Pinsho.

La ciudad era, además, refugio de la gente jornalera, proveniente del campo, que estaba a medio camino entre la servidumbre y el asalariado libre. Los indígenas acudían a la ciudad temporalmente a trabajar como peones en las construcciones y obras públicas, o como cargadores. En "oficios de los indios", como se decía de manera naturalizada. Algunos de ellos habían sido incorporados a la ciudad o estaban en proceso de serlo, pero sus costumbres y formas de vida tenían aún mucho de campesinas. Al revisar el cuadro de contraventores de la ciudad de Quito en 1899 uno se topa con un grupo numeroso de jornaleros (1.285) al que habría que sumar muchos de los que constan en el 
cuadro como agricultores (148) Se puede observar que en ese cuadro no constan obreros manufactureros y menos aún fabriles aunque sí artesanos.

Es verdad que en la ciudad se reproducían las fronteras étnicas, pero sus condiciones no eran las mismas que las de la hacienda. Con esto no me aventuro a decir que fuera mejor o peor, sólo que era distinto. La ciudad permitía, aún en el contexto de un sistema de relaciones y valores estamentales y jerárquicos, una cierta movilidad social y cultural. Aunque lo dominante era la oposición binaria que separaba lo blanco de lo indio, lo negro y lo cholo, en la vida social existían muchos procesos dinámicos. Dentro del mundo popular había lugar para una gran variedad de ocupaciones y oficios que se generaban como parte de la monetarización de la economía y de una división del trabajo que se desarrollaba más en extensión que en profundidad ${ }^{16}$. Ejemplo de esto último fue el desarrollo de las confecciones populares, el calzado popular y la juguetería de madera y hojalata entre los anios treinta al cincuenta del siglo $\mathrm{XX}$. Estas ocupaciones respondían a una creciente demanda, orientada hacia nuevos consumos populares; quienes las realizaban no eran necesariamente las industrias fabriles sino costureras, carpinteros, zapateros y otros artesanos individuales o como parte de empresas informales domésticas. Dentro de los sectores subalternos existían diferencias de acuerdo con sus actividades así como por su ubicación en el espectro social o a la condición de género: no era igual la situación de un indígena, un mestizo o un blanco venido a menos, o de un hombre y una mujer, aunque tuvieran igual fortuna. Los sectores populares se diferenciaban tanto por sus oficios como por su adscripción étnica o racial (el oficio de maestro albañil, por ejemplo, era propio de indios, mientras que los panaderos o los peluqueros eran, por lo general, mestizos, igualmente la servidumbre estaba formada sobre todo por mujeres) Otro elemento que diferenciaba a los sectores populares era su mayor o menor grado de autonomía con respecto a las elites.

La disponibilidad de fuerza de trabajo fue uno de los requerimientos para la modernización de la ciudad pero existía una contradicción entre esos requerimientos modernos y las formas poco modernas de utilizar la mano de obra. El problema no era sólo el concertaje, que sujetaba a la población indígena a las haciendas, sino la creciente oposición de esa población a someterse a realizar trabajos fuera de su voluntad. Existía una dinámica de trajines e intercambios en la que esa población de los alrededores de Quito estaba inserta desde la colonia y que se veía alterada por las crecientes demandas urbanas.

No sólo la ciudad sino los particulares se veían afectados por la falta de mano de obra. En Guayaquil ese servicio había sido modernizado gracias a las agencias de colocaciones que funcionaban en coordinación con la Policía, mientras que en Quito esto seguía dependiendo de redes, clientelas y 
relaciones personalizadas, algo que en la primera mitad del siglo XX había entrado en crisis debido al crecimiento de la urbe y el incremento de las personas desconocidas y poco conocidas en búsqueda de trabajo. Se suponía que el arrendamiento de servicios de nodrizas, cocineras, lavanderas, muchachas de mano, pajes, cocheros, debía de ser normado por la Intendencia, lo cual generalmente no funcionaba. En principio, no sólo los gremios sino los domésticos debían inscribirse en la Policía. Se trataba de que estos servicios fuesen registrados en un libro especial que constaba en la oficina de investigaciones y de pesquisas. El objetivo principal de esa disposición consistía en precautelar a los ciudadanos de los "falsos sirvientes". El crecimiento de la ciudad como resultado de las migraciones daba lugar al aparecimiento de sectores sociales e individuos de difícil clasificación, que no entraban en los parámetros de la antigua sociedad patrimonial. Eran los llamados vagos y sospechosos. Al contrario de lo que generalmente se piensa este proceso de llegada a la ciudad de individuos "inclasificables" comenzó ya en la segunda mitad del siglo XIX. Entre los contraventores calificados por las comisarías de Quito en el año de 1899 constan 128 vagos y 114 sospechosos. Igualmente se registran 119 menores extraviados. ${ }^{17}$ Sólo en ese ańo fueron entregados por los comisarios 71 menores: 51 a talleres y 20 a casas particulares (de estos 29 eran mujeres). ${ }^{18} \mathrm{La}$ dinámica que llevaba a la persecución de vagos, sospechosos y menores descarriados no era el disciplinamiento necesario para la industria, sino la de una sociedad en la que se conjugaban las formas modernas con los sistemas rentísticos de utilización de la mano de obra.

La vida popular urbana se mueve en estos espacios contradictorios, de sujeción y autonomía y es en medio de eso donde se desarrolla su cultura.

\section{El comercio y los consumos populares}

Un mundo más fluctuante era el de los trajines callejeros; aparte de las vendedoras y vendedores con puestos fijos en los mercados y tiendas, había un grupo numeroso de regatonas que se movía por toda la ciudad con sus productos. Se trataba de un comercio ambulante de productos agrícolas, leña, ropa, alimentos preparados. Buena parte de ese comercio provenía de los pueblos y comunidades de indios cercanos a la urbe, pero también de indígenas y mestizos urbanos entre los cuales ocupaban, como ya se dijo, un lugar destacado las mujeres. A más de esto estaban los molinos y hornos de pan, los lugares donde se preparaban y vendían las chichas, las picanterías, las traperías y cachinerías. Muchas de esas actividades se desarrollaban en espacios característicos, otras en distintos sitios de la ciudad. El Aguarico era conocido por sus chicherías mientras que la calle Chile era el lugar de las traperías y cachinerias. 
Todo hace pensar que el comercio popular imprimía una dinámica paralela a la ciudad y que esa dinámica no necesariamente se oponía a la del comercio formal. La parte del comercio popular que funcionaba en lugares estables como pulperías, tiendas de abarrotes, barracas, cajones estaba, a su vez, estrechamente relacionado con el comercio ambulatorio. Pero no sólo se trataba del comercio popular, ya que también las casas de comercio estaban relacionadas con el comercio al detalle. Justamente en los albores del primer centenario de la Independencia (1922) hubo un debate sobre si se debía permitir o no que las buhoneras siguieran manteniendo sus pequeńos negocios en la Plaza Grande. En el debate se mostraba que ellas respondían a las necesidades de los almacenes y comercios formales, lo cual era parcialmente cierto. A esta dinámica callejera habría que sumar la de los arrieros, cargueros y carreteros, que facilitaban el intercambio de productos entre la ciudad y el campo y dentro de la misma ciudad. Ni siquiera con el ferrocarril, el tranvía y, más tarde, con la introducción de transporte motorizado, éstos desaparecieron del todo.

Sería equivocado pensar que no se reproducían las fronteras entre la población indígena y la blanco mestiza, aspecto en el que acertadamente pone énfasis Guerrero $^{19}$. Pero, a diferencia del campo la ciudad se caracterizaba por un flujo constante de gente, productos, personas e información, lo que imprimía un ritmo distinto a las relaciones cotidianas. El comercio, en particular, introducía una dinámica de tratos y relaciones diferente al que se daba en el campo.

Un rubro importante del comercio era la carne. El faenamiento de animales en mataderos públicos buscaba garantizar su calidad, pero también el cobro de tasas por parte del Municipio. Las carnicerías funcionaban tanto en la zona urbana como en las parroquias constiuyendo una parte importane de la vida popular. Uno de los pedidos que hacía el Intendente de Policía al Ministro del Interior, en el ańo de 1917, era la presencia de celadores en el matadero, con el fin de evitar los escándalos y los abusos de los introductores de ganado. De acuerdo al mismo documento, sin la presencia de ellos sería imposible conservar la disciplina en los mataderos.

El impuesto "de Rastro" se cobraba hacia el ańo 1884 tanto en Quito como en las parroquias de Santa Prisca, Guapulo, Magdalena y Chimbacalle. ${ }^{20}$ Estas parroquias tenían una fuerte composición indígena. De acuerdo con disposiciones que no siempre se cumplían, nadie podía despostar ganado sin conocimiento del teniente político, ni se podía vender la carne fuera de la población, a no ser que se la trasladase en carretas de modo que "no se oree demasiado". Lo más frecuente era llevar el ganado en pie hasta los mataderos de la ciudad. Los llamados introductores de carne eran, generalmente, mestizos que recorrían los campos comprando y revendiendo en Quito, pero es muy probable que en ese negocio hayan participado algunos indígenas. ${ }^{21} \mathrm{La}$ forma en que se transportaba 
la carne preocupaba a los médicos higienistas. Según sus descripciones se lo hacía en carretas sucias y deterioradas "ofreciendo un espectáculo nada estético". ${ }^{22}$

Algo parecido a la carne sucedía con la leche y con el pan: no tenía sentido traerlos desde muy lejos ya que pasaba mucho tiempo antes de de que pudieran ser consumidos. Sólo con el ferrocarril comenzaron a llegar productos perecibles de zonas más lejanas.

Los médicos salubristas estuvieron preocupados por las condiciones higiénicas de las carnicerias, panaderías y otros establecimientos populares. En una denuncia presentada en 1911 se decía que los panaderos dormían sobre las lonas. ${ }^{23}$ No solo los locales no eran adecuados sino que servían de dormitorio. En la sierra el pan era producido con harina nacional mientras que en Guayaquil la mayoría de la harina era importada. De acuerdo a Espinoza Tamayo esa harina era de buena calidad pero se contaminaba en las bodegas y en las panaderías. En su informe ${ }^{24}$ se decía que si bien la harina importada que se consumía en Guayaquil era de buena calidad para la panificación, la fabricación del pan adolecía de muchos defectos, que redundaban en su calidad:

En primer lugar, los locales de las panaderías no son apropiados y sólo uno en toda la ciudad reúne los requisitos debidos. La mayor parte no tiene más pisos que la tierra, son faltos de luz, con paredes y cielo raso lleno de suciedades; las mesas de amasar o artesas son de madera, rara vez se las limpia y sobre ellas se forma una capa de harina, masa y tierra, alterada y pútrida.

De acuerdo con ese documento el pan se fabricaba con levadura de pasta ácida, que se preparaba mezclando tres partes de harina, dos de agua y una de lúpulo. La pasta era abandonada a la fermentación en un barril de madera de 10 a 12 horas hasta que había aumentado de tamaño. Esta pasta servía de levadura madre pero "casi siempre" el "exceso de acidez" alteraba la calidad del pan. Esta pasta madre se la mezclaba con harina y agua y se la dejaba en reposo durante dos o tres horas. El amasado se lo hacía generalmente a mano a excepción de unas pocas panaderías que, de acuerdo con este documento, ya empleaban el amasado mecánico. "Luego de este primer amasado la masa es amasada de nuevo, cortada y amoldada de acuerdo a la forma del pan".

La situación de las panaderías en Quito no era distinta. Los higienistas habían desarrollado una preocupación por su estado. En 1913 se crea el laboratorio municipal que se ocupa del análisis de la calidad de los alimentos, incluido el pan. En un informe presentado por la Dirección de Higiene Municipal en 1922 se dice que fueron inspeccionadas 153 panaderías, 4677 cantinas y abarrotes 633 lecherías, 474 tercenas, 1165 hoteles y figones, 713 mercados $y$ ventas ambulantes, 213 puestos de ventas de dulces y frescos, 11 fábricas. ${ }^{25}$ 
Estas visitas estaban dirigidas a prevenir las pestes pero en momentos de epidemia no eran suficientes. La estrategia adoptada por la Dirección de Higiene era acudir a los lugares donde había sospechas de que se estaba iniciando una epidemia con el fin de controlarla y evitar que se expanda. Se trataba de una medicina preocupada por el medio, que sabía que las epidemias generalmente se iniciaban en los barrios pobres para luego pasar al resto de la ciudad.

Uno de los problemas con que se enfrentaba la Dirección de Higiene Municipal era que contaba con sólo nueve inspectores de los cuales uno se dedicaba a visitar las panaderías, cuatro inspeccionaban las lecherías y el resto hacía visitas domiciliarias. Esto llevaba a que se descuiden otras áreas como las peluquerías y los mercados. A más de esto los inspectores y médicos tenían dificultades de moverse en la ciudad debido a la falta de nomenclatura en las calles y casas de muchos barrios y la falta de colaboración de los más pobres. ${ }^{26}$ Aunque el control estaba orientado sobre todo a la zona central no era menos importante evitar los factores de contagio a través de productos que iban de uno a otro lugar como la leche, el pan, la carne. Pasaban por distintas condiciones y por diferentes manos y eso los hacía peligrosos.

Una de las cosas que particularmente preocupaban a los higienistas era la transmisión de enfermedades a través del pan. Es por eso que pedían se exija certificados médicos a todos los que laboraban en las panaderías. De acuerdo a algunos médicos que se inscribían en esa línea de medicina social, el trabajo nocturno afectaba la salud de los trabajadores y esto era, a su vez, una de las causas de la propagación de enfermedades La tradición de elaborar el pan por la noche estaba relacionado con la idea equivocada (según se decía) de que se debía vender el pan del día, pero lejos de lo que se pensaba, el pan del día no era saludable y no justificaba un tipo de trabajo que provocaba desgaste físico y envejecimiento prematuro. El trabajo en las panaderías preparaba el camino a la tuberculosis, uno de los factores que más contribuían a la degeneración de la raza.

Todo esto formaba parte de una preocupación por el cuerpo útil de la población, pero estaba también relacionado, además, con las acciones de los propios trabajadores para mejorar sus condiciones de trabajo, en contradicción con las exigencias de los propietarios y maestros panaderos.

\section{Los espacios de trabajo y de habitación}

Buena parte de la gente del pueblo y de los sectores medios (maestros y maestras de escuela, empleados de comercio y de la administración pública, estafetas de correos) habitaba -según sus posibilidades-en una, dos o tres cuartos en las casas del actual centro histórico. Existía una suerte de estratificación 
en el interior de las casas de acuerdo al mayor o menor número de piezas que ocupaba una familia, el grado de iluminación, su ubicación dentro del espacio interior, pero sobre todo por el nivel de decencia ${ }^{27}$ de los ocupantes. Aún cuando muchas de las familias acomodadas comenzaron a mudarse del centro convirtiendo sus antiguas moradas en casas de inquilinato, las que no lo hicieron, o no pudieron hacerlo, evitaron llenar sus casas de desconocidos, optando por arrendar piezas (en lo posible) a "gente decente".

En esas mismas casas habían sido instaladas tiendas de comercio, talleres y pequeñas industrias domésticas como las panaderías. Como señalaban algunos informes de la Dirección de Higiene Municipal, se trataba de locales improvisados, poco apropiados para tareas artesanales o para la elaboración de comestibles como el pan. Debido a la estrechez de los locales buena parte de los artesanos se veía obligada a utilizar la calle o a invadir los patios interiores y corredores para convertirlos en lugares de trabajo; pero esos espacios eran, al mismo tiempo, los del vecindario, donde jugaban los nińos, charlaban los mayores y se tendía la ropa.

Aunque había diferencias en los niveles de ingreso y de prestigio entre los habitantes de esas casas se veían obligados a compartir muchos aspectos de su cotidianidad. No quiero hablar con esto de relaciones idílicas sino de formas de organización del espacio social propias de las casas de vecinos en una época determinada. Es posible que el sentido de la privacidad y de separación con respecto al otro haya sido mucho menor que en el presente pero eso daba lugar a un control más directo sobre la vida personal. Muchas de esas casas eran verdaderos laberintos. Los médicos higienistas y los publicistas de la primera mitad del siglo XX se empeñaban en pintarlas como lugares oscuros y sucios. No contamos, sin embargo, con la memoria de la gente que pobló esos espacios.

Las fondas, figones, cantinas, chicherías, cafés, sitios de refrescos y otros establecimientos de fabricación o expendio de alimentos destinados al consumo inmediato constituyen la parte más difícil con que tropieza la Oficina de Sanidad. La mayor parte de estos establecimientos, en especial los figones, son cuartuchos oscuros, casi sin ventilación, húmedos, con pisos en deplorables condiciones. ${ }^{28}$

Muchos de los talleres, panaderías, tiendas de abarrotes eran, como ya seńalé, lugares de habitación. Un cuadro del Instituto de Previsión Social, del año 1937 muestra que el 60\% de las familias se alojaba en una sola pieza, de las cuales el $21 \%$ no tenían revestimiento y un 30\% carecía de ventilación, acceso libre al agua y servicios higiénicos. ${ }^{29}$ Los higienistas veían en el estado de los alojamientos una de las causas del debilitamiento de la raza.

El estado de suma pobreza en que se encuentran las masas del pueblo, cuyas familias se hallan hacinadas en habitaciones húmedas, 
oscuras y estrechas, familias que viven, en muchas ocasiones en una sola pieza, que al mismo tiempo sirve de cocina y dormitorio. ${ }^{30}$

Promedio de habitaciones por familia

En $160,1 \%$

En 2 13,6\%

En 3 7,1\%

En 4 4,7\%

En $53,4 \%$

En $63,1 \%$

En $83,6 \%$

En $104,4 \%$

Fuente: Estudio numérico y económico de la población de Quito, Departamento Médico del Instituto Nacional de Previsión Social, marzo de 1937

Un porcentaje alto de piezas no tenían ventanas, debido a que eran el resultado de la subdivisión de habitaciones más grandes. La mayoría de lugares de venta y fabricación de productos como el pan eran oscuros, sin ventilación y con los pisos de tierra. En cuanto a la servidumbre buena parte de ella carecía de un lugar propio, en muchas ocasiones inclusive no contaba con un espacio definido dentro de la casa de sus patrones: "dormía donde podía". Pero esto pasaba también con los oficios (por ejemplo en algunas panaderías los aprendices descansaban en una tarima junto al horno o en pequeńas habitaciones que servían a su vez de bodegas). Otra parte de la población de la ciudad vivía, en realidad, en los pueblos y comunidades cercanas. Cuando se quedaba en Quito pecnotraba en los zaguanes de algunas casas en barrios populares como San Roque. ${ }^{31}$

A partir de la segunda década del siglo XX se fueron formando asentamientos populares "de nuevo tipo" denominados "barrios obreros", como Chimbacalle, el Aguarico, la Colmena, pero que, en realidad, agrupaban tanto a obreros fabriles como a empleados de comercio, artesanos, trabajadores independientes, negociantes y "negociantas", maestros albañiles. Muchos barrios, como San Juan, el Aguarico, se fueron construyendo a lo largo del tiempo con base en el esfuerzo de la gente y a mingas. Entre los habitantes de los barrios populares se desarrollaba un fuerte sentido de localidad o de pertenencia. La mayoría estaba adscrita a un santo patrono y celebraba sus fiestas. El año de 1928 el concejo municipal reglamentó la formación de barrios nuevos, pero un control más o menos efectivo de esas urbanizaciones no fue posible, sino muchos años más tarde y por un tiempo relativamente corto (hasta la década de 1960, cuando comenzó un nuevo ciclo de expansión de la ciudad). 
En una declaración municipal de 1939 se decía que el problema de los barrios nuevos venía de tiempo atrás. "El error es el de haber permitido la formación de barrios nuevos, sin sujeción a un plan científico de urbanización y la ninguna exigencia para con los empresarios que se contentaron con dividir terreno por medio de calles aún más estrechas que las de Quito Colonial, dejando al Concejo las obras de urbanización correspondientes, lo que tuvo por fuerza, con el paso de los años, que pesar gravemente sobre los intereses de la ciudad" ${ }^{32}$ Los barrios populares que se había formando en Quito carecían de servicios básicos como canalización y agua potable, así como de escuelas, espacios destinados a plazas. Los ubicados en las partes altas como la América, el Dorado, el Panecillo se convertían - de acuerdo a la percepción de los ańos cuarenta - en focos de infección desde donde corrían los deshechos y las aguas servidas que invadían las partes bajas de la ciudad. En realidad pestes como las de la tifoidea no hubieran podido ser enfrentadas sin la organización de la gente de los propios barrios. ${ }^{33}$ Hacia los ańos treinta los objetivos salubiristas ya habían sido incorporados a la vida popular. Eso permitió ampliar la acción del estado, en momentos en los que los recursos eran escasos._La mayoría de los barrios nuevos eran el resultado de lotizaciones hechas por los dueńos de haciendas y de fincas, con el mínimo inversión, obedeciendo más a un sentido rentístico que empresarial. Un registro de 1961 decía que "los sectores populares se ubican en los llamados barrios de las colinas, en calles estrechas, mal trazadas, sin pavimento. Las casas de uno o dos pisos de apariencia modesta o pobre" ${ }^{34}$

\section{La dieta popular}

La dieta popular de la primera mitad del siglo XX incluía generalmente alguna porción de pan o de carne, pero en momentos de crisis uno de sus indicadores más claros, para los sectores populares, era su encarecimiento. Se trataba de una economía precaria, en la que estaban ausentes los lujos y en la que las posibilidades alimentarias dependían del precio de la harina de trigo, la máchica, la panela, la manteca, el arroz, las papas antes que de otros productos que sólo eran consumidos por los grupos de mayores ingresos. En épocas de depresión como las de los ańos treinta y cuarenta del siglo XX, las capas populares y medias tenían dificultades para cubrir sus necesidades mínimas. "En esos años el mayor interés de obtener una beca escolar era poder alimentarse". ${ }^{35}$ Después del proceso liberal las instituciones de la caridad y las de la beneficencia pública competían en el intento de dar auxilio a los más pobres. No sólo la iglesia organizaba reparticiones de alimentos y ayudas, como el llamado Pan de San Antonio, sino que el Municipio creaba comedores en las escuelas y comedores populares en los barrios, siendo posiblemente uno de los primeros el que funcionaba detrás de la Caza de Rastro: 
El ilustre Concejo muy inteligentemente impidió la venta de comidas en el interior y exterior de la plaza: pero el Sr. Presidente de entonces, Sr. D. Pedro Traversari, sagaz y humanitariamente hizo construir una ramada a la parte occidental de este establecimiento. A esta acude en busca de almuerzo un enjambre de trabajadores, vendedores y hasta nińos que sin tener pan ni lumbre en su casa, se proveen allí de un alimento aunque deficiente, barato. ${ }^{36}$

Estos comedores estaban orientados a servir a la "porción infortunada y Miserable que forma el pueblo". La cita es de 1910 y evidencia la existencia de capas de población desprotegidas (sobre todo llama la atención la referencia a nińos) expresión no tanto de la reproducción del pasado colonial en el presente, como de las propias condiciones de desigualdad social de la modernidad temprana. Buena parte de los que acudían a esos comedores debía ser inmigrantes que trabajaban como cargadores en los mercados o peones de las construcciones, jornaleros, hierbateros, vivanderas y otras ocupaciones asignadas a indígenas. Otra parte debió estar integrada por los sectores de la llamada plebe urbana. En el ańo 1946, Velasco Ibarra decretó que las fábricas organicen para sus trabajadores almacenes de artículos de primera necesidad. Las harinas de trigo y de cebada estaban incluidas entre esos artículos, al igual que el arroz, la manteca, los fideos, el chocolate, el café, el maíz, las papas, las menestras. El Municipio, por su parte, tenía organizados 3 comedores populares en los que se servían 1.156 comidas diarias. También tenía organizado almacenes de artículos básicos "para consumo del pueblo". Existía preocupación por el clima de descontento social que podía provocar el alza del precio de los bienes de subsistencia. ${ }^{37}$

El aumento del precio del pan y de otros productos populares era un indicador importante del incremento del costo de la vida. De acuerdo con un informe del Instituto Nacional de Previsión del año 1937, el 52\% de las familias quiteñas de cinco miembros se alimentaba con lo poco que se podía adquirir con uno a dos sucres diarios. El costo de algunos alimentos, entre los que se incluían distintos tipos de harina era, según ese informe, el siguiente:

Harinas de cereales 0,25 la libra

Harinas de legumbres 0,30

Legumbres verdes 0,25

Tubérculos 0,15

Grasas 1,55

Panela 0,30

Carne 0,70 
Esto significaba que una familia únicamente podía proporcionar a sus miembros una dieta que no rebasase un promedio de 0,20 a 0,40 sucres diarios. Cualquier incremento de esos precios conducía a un desmejoramiento de la alimentación. La dieta popular consistía en una colada de media libra de harina, 30 gramos de carne y 0,05 de panela y en el mejor de los casos, en una colada de media libra de harina, media libra de papas, 100 gramos de carne, 100 gramos de leche y O,10 sucres de panela ${ }^{38}$. La harina de cebada, de plátano o de haba se utilizaba para hacer coladas mientras que con la de trigo se hacían empanadas o bunuelos, sólo en situaciones especiales. El pan, generalmente, se utilizaba para acompañar una taza de agua de panela en el desayuno o en la merienda, pero en ninguna casa se lo podía usar de manera indiscriminada. En momentos de crisis ni siquiera se podía cubrir estos mínimos. Como recordaba Don Nicolás Pichucho:

Los que no tenían hacían un cafecito o chocolate en agua y hacían chapo. No tenían para pan. Mi hermano madrugaba para hacer traposa con mapaguira y máchica. En veces se hacía pinol con la rapadura. Mi mamá que era carnicera cambiaba la rapadura con carne. ${ }^{39}$

La gente vivía al día sin entender el funcionamiento económico ni de las finanzas públicas, por eso el disgusto popular se orientaba a lo más cercano: el tendero, el propietario de la covacha, los expendedores de carne, el dueńo de la casa de inquilinato. Este disgusto se expresaba en el discurso como lucha contra los acaparadores de la harina, los adulteradores de la manteca o los comerciantes que "sin un rastro de pudor y buscando solamente una desalentadora utilidad para saciar su codicia, venden los diferentes artículos con pesas y medidas falsas, que perjudican hasta en cuatro y seis libras por onza al comprador". ${ }^{40}$

Al momento de sacrificar alguno de los productos de la dieta popular uno de los más afectados era el pan ya que éste subía de precio o, en otros casos, los panaderos disminuían su calidad y su tamaño. Eso conducía al cierre de panaderías, sobre todo de las más populares.

Hace algún tiempo que el precio de los artículos de primera necesidad ha subido de manera escandalosa sin razones que justifiquen semejante procedimiento. Los acaparadores de harinas, alegando la plaga del "polvillo", que no existe en proporción alarmante, ni mucho menos, elevaron el valor de este artículo, hasta el extremo de que varios productores de pan manifestaron ya el propósito de cerrar sus panaderías. Pues que actualmente se vendía grajeas de harina en lugar del pequeño pan que antes se ponía al expendio diario. De donde resulta que la gente poco acomodada, máxime la carente de recursos, ya no pueda darse el lujo, porque lujo es en realidad, de adquirir el pan, alimento de primer orden para la vida humana. ${ }^{41}$ 
Lo que se temía en los años treinta del siglo XX era el desborde popular ya que "el hambre es mala consejera". Es posible que ya existiesen antecedentes de motines de subsistencia, o por lo menos de tumultos desde el siglo XIX. De lo contrario el Código Penal y de Enjuiciamiento Criminal de 1872 no hablaría de acciones "que perturban el orden público en los mercados con el propósito de producir saqueos, o simplemente de obligar a las vendedoras a deshacerse de mercancías por un precio inferior" "42. En todo caso, las formas en que se resolvían los conflictos no debieron ser iguales en el siglo XIX que en la primera mitad del siglo XX, cuando las relaciones patrimoniales entre las élites tradicionales y la llamada plebe habían entrado definitivamente en crisis. En los años treinta y cuarenta se ensayaban distintas respuestas al descontento popular, al mismo tiempo se llamaba a la sensibilidad de la sociedad para paliar los efectos de las crisis. Desde la iglesia se recogían limosnas para los pobres o se repartían alimentos, entre los que se incluía el pan. A esto se sumaba la acción de benefactores y benefactoras, calificadas por muchos como "poco discretas" ya que habían pasado a formar parte de las representaciones mundanas antes que de "la auténtica caridad cristiana".

En los momentos actuales en que el Ecuador se debate en la miseria, padeciendo una crisis económica nunca vista, es preciso que hablemos de caridad y de socorro al pueblo hambriento que ya no puede adquirir lo que requiere para satisfacer sus necesidades más urgentes. Hoy como nunca hemos visto subir a las nubes los precios de todos los artículos de primer consumo, ya nada alcanza al obrero y al empleado particular para llenar su reducido presupuesto: en vano suprime de sus comidas el pan y la carne; sin efecto reduce a dos los platos de su mesa. ${ }^{43}$

La crisis amenazaba las bases de la organización jerárquica y estamental de la sociedad. Los católicos más cercanos a la vida popular llamaban a desarrollar cruzadas de solidaridad con los obreros parecidas a las que se había organizado en otras ciudades como Barcelona:

Hoy, lo primero es dar de comer al hambriento, no arrojando un pan, o un centavo, que no satisface nada, sino estableciendo comedores públicos en donde vayan a almorzar los obreros, los sin trabajo, los escolares que, en un momento dado, no tienen lista su comida y vuelven muchas veces a sus tareas en ayunas, Los avaros y los de grandes rentas y fabulosos sueldos no saben de estas secretas tragedias del hambre; pero nuestras matronas y doncellas deben conocerlas, porque son los únicos capaces de llevar a cabo los comedores para pobres, como se han establecido en otras partes. ${ }^{44}$ 
En las primeras décadas del siglo XX el sentido mismo de la caridad estaba en discusión y el pan servía como metáfora. En esos años se planteaba que la preocupación debía ser puesta en la familia del obrero (el cuerpo útil de la población) antes que en repartir limosnas que a nada conducían. Si bien había que procurar que la gente tenga pan era mejor enseńarle que se lo gane con el sudor de su frente.

\section{La cultura popular en la modernidad temprana}

¿Cómo se estructuraba la cultura popular en la modernidad temprana? Por un lado había una cierta diferenciación entre la "cultura artesanal" y las del resto del pueblo. A eso había contribuido la escolarización de los hijos de los artesanos, la Escuela de Artes y Oficios y ya en el siglo XX el Liceo Municipal Fernández Madrid dirigido a dar capacitación técnica a las mujeres. ${ }^{45}$ Por otro lado, y a pesar de la separación entre República de Indios y Españoles que atravesaba el conjunto de la sociedad, existían muchos espacios compartidos, sobre todo entre los sectores subalternos (sean indios, negros, mestizos o blancos pobres) relacionados tanto con el trabajo y los trajines en calles, ferias y plazas, como con las celebraciones religiosas y mundanas. Estamos hablando de una sociabilidad común y espacios donde ésta se expresaba, prácticas de intercambio, consumos culturales comunes, costumbres similares, una religiosidad popular paralela a la religiosidad seria. Incluso la élite no era ajena a compartir ciertos elementos culturales que en términos generales podríamos llamar barrocos, aunque, lógicamente, existían procesos de separación y diferenciación crecientes.

Me da la impresión de que en medio de los cambios provocados por la primera modernidad la vida popular se agrupaba, en buena medida, dentro de lo que podríamos denominar cultura callejera o inclusive muchedumbre. Esta noción nos remite a la idea de mezcla o de tendencia a la mezcla al mismo tiempo que a la idea de flujo. Aún cuando buena parte de la población seguía siendo parte de una "casa" o de un taller (tenía la calidad de "propio", un término irónico que utilizaban la élites para refrerise a sus subordinados) ${ }^{46}$, existían muchos sectores en "condición fluctuante". Bajo esa situación se daba la posibilidad de que un individuo pase de un estado a otro. Larissa Lommitz (2001) hablaba, refiriéndose a la ciudad de México, de "cazadores recolectores" a la caza de oportunidades. Los estudios sobre la clase obrera inglesa en los siglos XVIII y XIX dan cuenta de situaciones semejantes, donde no existe una separación tajante entre la casa, el taller, el vecindario así como entre lo público y lo privado. Las posibilidades de vida popular dependían de su inserción en redes que incluían tanto a pares como a no pares. Vivir en la ciudad suponía 
saber moverse en esas redes, algo que no siempre era posible para un campesino recién llegado a la ciudad. Este podía formar parte de las redes que servían en los mercados o en la estación del tren en Chimbacalle, o incorporarse como cargador en un molino. ¿Pero qué posibilidad tenían de insertarse en las redes que ocupaban un lugar más alto dentro de la estratificación social como las de los aprendices de sastres o de panaderos, los dependientes de almacén y empleados de comercio?

Este flujo de una ocupación a otra, de una situación a otra respondía tanto a condiciones económicas como sociales. Un panadero podía cambiar de oficio o pasar temporalmente a la desocupación. Las personas se movían en el interior de círculos de relaciones e intentaban ir de un círculo a otro, dentro de situaciones inestables. Al mismo tiempo esa inestabilidad laboral provocada por la modernización podía ser percibida como una virtud, ya que era expresión de cierta autonomía. Lo más seguro era el mundo de las casas, mas esa seguridad era a su vez un peso muerto: carecía de futuro. La revolución liberal provocó movilidad. Muchos hombres del pueblo fueron incorporados a las fuerzas militares conservadoras y liberales, las mujeres se desplazaron con las tropas, alimentando a sus críos como podían. Manuel Terán, panadero, formó parte del grupo de montoneros detenidos en el penal durante las luchas alfaristas. Rafael Torres, zapatero, fue elevado al rango de teniente por el propio Alfaro, pero no por eso abandonó su oficio. ${ }^{47}$ En el ańo 1916 fue acusado de robo pero aun cuando admitió haberlo hecho pensaba que fue algo ocasional. ${ }^{48}$

Buena parte de los quiteńos venía de afuera, sobre todo de las parroquias y ciudades cercanas. Las ocupaciones eran variables, así como sus lugares de residencia. Muchos tenían doble domicilio, en la ciudad y en su lugar de origen. Los que no formaban parte de la servidumbre de las casas cambiaban fácilmente de ocupación. Muchos inclusive pasaban de la legalidad a la ilegalidad y viceversa con relativa facilidad. Entre los detenidos por la Policía por pequeńos actos delictivos muy pocos se declaraban vagos. Mercedes Díaz soltera, nacida en Carapungo y residente en Quito, de oficio cocinera, no tenía problemas en ocuparse como descuidera cuando se presentaba la ocasión. El $1^{\circ}$ de diciembre de 1913 entró a comprar a la carnicería de Tránsito Páez ubicada en la calle Colombia y al ver que no se encontraba nadie en la tienda tomó para sí una suma de dinero. Pero el dinero sustraído "también me robaron el mismo día porque estuve bebiendo en una cantina de San Blas y me había quedado dormida y me habían sacado la plata del seno". ${ }^{49}$ Andrés Simbaña, nacido en Calderón pero residente en Cumbayá y ocasionalmente en Quito, de oficio comerciante, se hizo de dos vacas que "encontró en el camino de Amaguaña" y las llevó a vender en la Capital. ${ }^{50}$ Las personas se movían en espacios informales. Esto no quiere decir que no existieran soportes: en primer lugar el de la 
familia, la comunidad, el barrio, pero también el de las casas. No se trataba de una muchedumbre anónima y sin lugares de anclaje, sino de desplazamientos en distintas direcciones y a partir de ejes.

Es cierto que existía una cultura hegemónica cuyo peso se expresaba al momento de las "decisiones nacionales" así como en la diferenciación entre lo público y lo no-público. Se trataba de sentidos incorporados relacionados con el honor o con el buen gusto, que condicionaba al conjunto de la población, pero se matizaban en la vida cotidiana por otros elementos, provenientes de una cultura popular tradicional, que se desarrollaba sobre todo (aunque no exclusivamente) en el interior de los sectores populares. Lo público concebido como lugar de todos era y es una ficción. No existía ni existe más que como representación relacionada con los espacios y símbolos patrios o lo símbolos religiosos. ${ }^{51}$

En la vida cotidiana de la primera mitad del siglo XX se daba una tensión entre una sociabilidad popular con la que muchas veces se veía comprometida la élite y una necesidad moderna de excluirla, primero, y de disciplinarla, más tarde. Mi criterio es que se vivían procesos contrapuestos. Por un lado existían puntos de encuentro y por otro de diferenciación. La propia elite había contribuido a reproducir elementos de una cultura en común, como parte de su proyecto hegemónico, sobre todo relacionado con la nación y con la religión, pero por otro lado esa misma élite desarrollaba criterios de distinción, en el sentido de Bourdieu ${ }^{52}$ basados en puntos de vista civilizatorios.

Lo que se dio desde el último tercio del siglo XIX fue una creciente incorporación a consumos urbanos, pero éstos no por eso dejaban de ser consumos populares. Un ejemplo eran las rifas y loterías clandestinas percibidas como lugares donde se pierden los hijos de familia, los dependientes de comercio e industria, los sirvientes domésticas, y "en donde se reúnen las personas notoriamente vagas" 53 . Aun cuando muchas veces se intentó prohibirlas éstas se siguieron organizando de manera abierta o clandestina. Hacía 1950 todavía se decía que las rifas y ruletas eran una costumbre arraigada en los quiteños. ${ }^{54}$ Otro ejemplo, al que ya se ha hecho referencia, fue el desarrollo de productos populares, como calzado barato, adornos de barro, hojalata, madera, juguetería popular para celebrar la fiesta típicamente urbana de las Navidades.

\section{Final}

La mayor parte de aspectos aquí planteados han quedado apenas esbozados. La investigación histórica sobre la vida social y cultural en el Ecuador, no ha tenido un nuevo impulso desde los años 1970 y 1980 . En el caso de Quito no sabemos, a ciencia cierta, cómo funcionaba la economía popular (el sistema de mercados, los oficios, la servidumbre, las actividades callejeras). Tampoco 
existe un registro de los motines de subsistencia (si es que se dieron) ni de su relaciòn con otras formas de decontento popular. El tema de los higienistas y su relaciòn con los consumos populares necesita, del mismo modo, ser desarrollado, así como los contenidos simbólicos de esos consumos. Dentro de todo esto, los aspectos culturales han sido los menos estudiados.

La ciudad en el siglo XIX albergó elementos de una sociedad barroca, de representación, en la cual tenían cabida distintos órdenes y estamentos sociales. El carácter corporativo y al mismo tiempo jerárquico, de la sociedad se expresaba en el ceremonial con la presencia de los oficios y cofradías, las organizaciones benéficas, las autoridades civiles y eclesiásticas, así como la participación de los indios y de la plebe urbana. Esto iría modificándose desde la segunda mitad del siglo XIX, pero sólo tomaría fuerza hacía las primeras décadas del siglo XX, cuando se profundizó el conflicto cultural en tono a la religiosidad, la fiesta y el uso popular de los espacios públicos. La vida popular urbana se caracterizaba, hasta avanzado el siglo XX, por un fuerte sentido social. No sólo se vivía de cara al público sino que se participaba de una gran cantidad de actividades públicas. Las formas corporativas garantizaban la existencia social e individual. Se trataba de una suerte de economía moral, instituida a partir de figuras como los oficios y cofradías, los barrios. Lo que se fue impoinendo con la modernidad fueron criterios civilizatorios que se expresaron en el ordenamiento de los espacios, su diferenciación y domesticación en términos de ordenamiento, pero también de limpieza étnica.

La sociedad quiteńa asistió a finales del siglo XIX y durante la primera mitad del siglo XX a un complejo proceso de transición de lo que denominamos una ciudad patrimonial, o seńorial, a la modernidad temprana. Los años veinte y treinta del siglo pasado constituyen un hito importante en ese tránsito. No hay que perder de vista que en esos ańos se fueron produciendo mutaciones fundamentales en la composición de las clases en Quito y que fueron momentos de fuerte agitación social ${ }^{55}$. No me refiero tan sólo al proceso de modernización terrateniente y de fortalecimiento del capital comercial, que provocó cambios en los comportamientos de las elites, en la línea de la secularización (aunque sin modificar su esencia rentista), sino al desarrollo de un nuevo tipo de sectores subalternos urbanos, con características propias, que les diferenciaban de los habitantes del agro y la vida rural, aunque algunos de ellos mantuviesen vínculos estrechos con el agro. Es cierto que desde los días mismos de la colonia existió una capa urbana ligada a los oficios y al mercado, pero tengo la sospecha de que sólo se puede hablar del aparecimiento de capas populares con hábitos de vida, intereses y características de algún modo diferenciadas y con cierto nivel de independencia con respecto a los patricios (o notables) urbanos y a las antiguas clases subalternas, a partir de esos ańos. 
Se trataba de un proceso más o menos largo de urbanización de la vida popular que avanzó hasta la segunda mitad del siglo pasado y que de alguna manera continúa reproduciéndose contemporáneamente en el seno de la población de origen rural que se va relacionando con la ciudad y con las formas de vida urbanas (con las migraciones este proceso ha adquirido ahora una dimensión planetaria).

\section{Notas e Referências}

1 Algunos aspectos de este texto han sido tomados del artículo inédito "La ciudad, el molino y los panaderos". Sus objetivos y enfoques son, en todo caso, distintos.

2 Eduardo KINGMAN GARCÉS. La Ciudad y los Otros. Quito 1860-1940. Higienismo, ornato y policía. Quito: Flacso, 2006.

3 Nociones como la de ciudad de Antiguo Régimen o la de ciudad señorial puede conducirnos a pensar en una sociedad estática y de una total dependencia con respecto a las elites. Las indagaciones de archivo y los testimonios nos muestran que no fue así. En el caso de las ciudades de los Andes está pendiente un debate entre una visión monumental de su historia y una historiografía crítica que asume la ciudad como un campo de fuerzas.

4 El texto es de Arthur Weibauer y ha sido citado en Maria-Louise KRETUER. ¿Dónde queda el Ecuador? Exilio en un país desconocido desde 1938 hasta finales de los ańos cincuenta. Quito: Abya Yala, 1997.

5 Una ordenanza de de 1867 diferenciaba el monto del impuesto a las chicherías que se debía pagar en la ciudad (ochenta centavos) del que se pagaba en las parroquias (cuarenta centavos) Además estaba prohibido vender chichas a tres cuadras de la Plaza Grande y se aumentaba en un centavo el impuesto por cada cuadra de cercanía a esa plaza.

6 Milton LUNA. Historia y conciencia popular: el artesanado en Quito. Quito: Corporación Editora Nacional, 1989.

7 ANH, Intendencia de Policía de Pichincha, documentos sin clasificar, 1923.

8 Dimas BURBANO. "Higiene Industrial" en Anales de la Universidad Central $\mathrm{N}^{\circ}$ 302, Tomo LIX, Diciembre de 1937.

9 Todavía en 1960 Telmo Paz y Miño $(1961,30)$ podía hablar de que "los barrios suburbanos (El Inca, Chaupicruz, Guápulo, La Magdalena) y los pueblos satélites (Cumbayá, Tumbaco, Cotocollao) proporcionan a la ciudad una gran parte de los productos de consumo diario, como legumbres, hortalizas, grasas y cereales." 
10 Andrés GUERRERO. La Semántica de la Dominación: el Concertaje de Indios. Quito: Ediciones Libri-Mundi, 1991.

11 "Cuadro demostrativo de calles, casas y tiendas de Quito" elaborado por el comisario municipal Manuel ENDARA. Diario El Comercio, 21 de septiembre de 1912.

12 Testimonio de Nicolás KINGMAN RIOFRÍO. Agosto de 2005.

13 AHMQ, Oficios y solicitudes, vol. 00225, folio 83 y ss.

14 El control del rastro estaba también relacionado con el abigeato Era práctica común entre los abigeos, mas frecuentemente llamados cuatreros vender el ganado en lugares lejanos para que fuesen despostados, y así no dejar huellas.

15 "Informe General de Higiene Urbana". En Boletin Sanitario, Quito: Imprenta Nacional, 1925, s.p.

16 Eduardo KINGMAN GARCÉS. La Ciudad y los Otros. Quito 1860-1940. Higienismo, ornato y policía. Quito: Flacso, 2006.

17 "Nómina de los contraventores calificados por las comisarías en el año de 1899". En Informe del Ministro del Interior y Policía al Congreso Ordinario de 1900. Quito: Imprenta Nacional.

18 "Cuadros de los menores entregados a los comisarios durante el ańo de 1899". En Informe del Ministro del Interior y Policía al Congreso Ordinario de 1900. Quito: Imprenta Nacional.

19 Andrés GUERRERO. "Una imagen ventrílocua: el discurso liberal de la desgraciada raza indígena afines del siglo XIX". En Imágenes e Imagineros. Representaciones de los indígenas ecuatorianos, Siglos XIX y XX. Blanca Muratorio (editora). Quito: Flacso, 1994, pp. 197-252.

20 AHMQ, Oficios y solicitudes Vol. 00225, folio 83 y ss.

$21 \mathrm{El}$ control del rastro estaba también relacionado con el abigeato. Era práctica común entre los abigeos, mas frecuentemente llamados cuatreros vender el ganado en lugares lejanos para que fuesen despostados, y así no dejar huellas.

22 "Informe General de Higiene Urbana". En Boletín Sanitario. Quito: Imprenta Nacional, año 1925.

23 AHM, Gaceta Municipal, 1910-1911, p. 309.

24 Luls ESPINOZA TAMAYO. "Contribución al estudio químico e higiénico de la leche, carnes, pescados, pan y huevos, que se consumen en la ciudad de Guayaquil" en Memorias del II Congreso Médico Ecuatoriano, reunido en Guayaquil de 9 al 12 de Octubre de 1930, Guayaquil: Imprenta la Reforma. 
25 Gaceta Municipal, "Labores de la Oficina" en julio y agosto. 113.

26 Gaceta Municipal, año 1933, p. 303.

27 Sobre la noción de decencia y su relación con el espacio, ver Marisol DE LA CADENA. Indigenas mestizos. Raza y cultura en el Cuzco. Lima: Instituto de Estudios Peruanos, 2004.

28 "Informe General de Higiene Urbana". En Boletín Sanitario, Quito: Imprenta Nacional, año 1925, p. 65.

29 Estudio numérico y económico de la población de Quito efectuado por el Departamento Médico del Instituto Nacional de Previsión Social, en colaboración con la Oficina de Higiene Municipal, en Instituto Nacional de Previsión. Boletín del Departamento Médico Social, Quito, marzo de 1937, p. 10.

30 Gaceta Municipal, "Labores de la Oficina" en julio y agosto, p. 310.

31 Testimonio de Don Nicolás PICHUCHO, agosto de 2004.

32 Gaceta Municipal, febrero de 1939.

33 Diario Ultimas Noticias, 24 de junio de 1940, p. 8.

34 Telmo PAZ Y MIÑO. Apuntes para la geografia urbana de Quito. Quito: Imprenta Municipal, 1961.

35 Testimonio de Nicolás KINGMAN RIOFRÍO, diciembre de 1994.

36 Gaceta Municipal, 1909-1910, p. 306.

37 AHM, Informe de José Ricardo CHIRIBOGA V., Alcalde de Quito, presentado a la ciudadanía, ańo 1950.

38 Estudio numérico y económico de la población de Quito efectuado por el Departamento Médico del Instituto Nacional de Previsión Social, en colaboración con la Oficina de Higiene Municipal, en Instituto Nacional de Previsión. Boletín del Departamento Médico Social, Quito, marzo de 1937, p. 13.

39 Entevista a don Nicolás PICHUCHO, enero de 2006.

40 "El Hambre que nos circunda". En Voz Obrera, N²0, 14 de junio de 1936.

41 "El Hambre que nos circunda". En Voz Obrera, N20,14 de junio de 1936.

42 Código Penal y Código de Procedimiento Penal. Nueva York: Imprenta Hallew y Reen, 1872.

43 "Verdadera Caridad". En Voz Obrera N²1, 21 de junio de 1936.

44 "Verdadera Caridad". En Voz Obrera N²1, 21 de junio de 1936.

45 Ana Maria GOETSCHEL. Educación de las mujeres, maestras y esferas públicas. Quito en la primera mitad del siglo XX. Quito: Flacso, 2007. 
46 Testimonio de Nicolás KINGMAN RIOFRÍO. Quito, agosto de 2007.

$47 \mathrm{ANH}$, Intendencia de Policía, documentos sin clasificar.

48 Ibid.

49 Intendencia de Policía de Pichincha, documentos sin clasificar.

50 IP, 18 de junio de 1952.

51 En la sociedad contemporánea lo público está además marcado por la cultura del espectáculo.

52 Pierre BOURDIEU. La Distinción. Criterio y bases sociales del gusto. Barcelona: Taurus, 1991.

53 Código Penal de 1872.

54 Diario Ultimas Noticias, 4 de diciembre de 1950, p. 15.

55 Luis Alberto ROMERO muestra en que medida el clima de agitación social contribuyó al desarrollo del "recelo de clase" en Chile. Según este autor si bien el clima revolucionario que vivía el mundo influyó, a modo de ejemplo, en los trabajadores chilenos, sus efectos más importantes fueron "como revulsivo para las clases propietarias". 